\title{
Validity and reliability of a calcium checklist in early elementary-school children
}

\author{
Lori Marcotte ${ }^{1}$, Erin Hennessy ${ }^{1}$, Johanna Dwyer ${ }^{2}$, Raymond R Hyatt ${ }^{1}$, \\ Jeanne P Goldberg ${ }^{1}$, Elena N Naumova ${ }^{3}$ and Christina D Economos ${ }^{1, *}$ \\ ${ }^{1}$ Gerald J. and Dorothy R. Friedman School of Nutrition Science and Policy, John Hancock Center for Physical \\ Activity and Nutrition, Tufts University, Boston, MA 02111 , USA: ${ }^{2}$ Gerald J. and Dorothy R. Friedman School of \\ Nutrition Science and Policy, Francis Stern Nutrition Center, Tufts-New England Medical Center, Tufts University, \\ Boston, MA, USA: ${ }^{3}$ Public Health and Family Medicine, Tufts University School of Medicine, Boston, MA, USA
}

Submitted 29 June 2006: Accepted 13 February 2007: First published online 1 August 2007

\begin{abstract}
Objective: To create, validate and assess the reliability of a checklist to measure calcium intake in children.

Design: Calcium intakes from a checklist and parent-assisted 24-h dietary recall were compared. Checklist reliability was assessed separately.

Setting: After-school programmes in the United States.

Subjects: Forty-two children (18 males, 24 females, age $=8.0 \pm 0.9$ years) participated in the validation analysis and 49 children ( 28 males, 21 females, age = $7.5 \pm 0.9$ years) in the reliability analysis.

Results: No differences in mean calcium intakes were found by method or gender. The checklist correlated well with recall among girls $(r=0.65, P=0.01)$ but not boys ( $r=-0.33, P=0.19)$. Agreement over time was above $80 \%$ for most foods. Conclusion: The calcium checklist is useful for assessing calcium intake among groups of 6-10-year-old children in settings that preclude parental assistance. More research is needed to improve accuracy among boys.
\end{abstract}

Keywords
Calcium checklist
Calcium intake
Field trials that aim to modify dietary behaviours require assessment methods that accurately measure key nutrients. Options for assessing dietary intake include the food frequency questionnaire (FFQ), 24-h dietary recall, food records and diet history ${ }^{1,2}$. However, young children lack the cognitive development, literacy and writing skills necessary to conceptualise their intake and self-report dietary habits, and thus limits the use of these traditional assessment techniques ${ }^{3,4}$.

The 24-h dietary recall provided by parents or by the child with parental assistance is generally accepted as a statistically reliable method for describing intake in $4-8$-year-old children ${ }^{1,2,5-7}$. One limitation of the parentassisted recall is that parents cannot verify reported food intake during times when the child is away from home ${ }^{8,9}$. Memory prompts, such as the use of previously collected food records ${ }^{10}$, may be helpful; parental assistance complements and clarifies the information initially provided by children during $24-\mathrm{h}$ recalls ${ }^{7}$. The FFQ is a popular method to assess usual intake among adults and adolescents $^{1,3,11,12}$, but it involves a generalised recall of usual food intake over many days or weeks, and that is beyond young children's cognitive capacity. Checklists of frequently consumed foods which require subjects to check items eaten over the past $24 \mathrm{~h}$ have also been used to assess intake of particular foods such as fruits and vegetables $^{12-16}$ or nutrients such as calcium ${ }^{17-20}$, fat $^{21-23}$ or fibre $^{24,25}$, but no such tool exists for assessing calcium intake in young children.

This study was part of a 2-year randomised controlled trial called The BONES (Beat Osteoporosis: Nourish and Exercise Skeletons) Project, which took place in afterschool programmes across Massachusetts and Rhode Island from 1999 to 2004. The goal of BONES was to maximise bone development, bone quality, muscular strength and calcium intake in 6-10-year-old children attending after-school programmes in diverse communities. At study onset, no tool was available for measuring calcium intake in early elementary-school children that did not involve parental assistance. Therefore, we developed a food checklist for use in BONES to estimate calcium intake over the previous $24 \mathrm{~h}$. This report describes the reliability and validity of the calcium checklist.

\section{Methods}

\section{Development of the calcium checklist}

The checklist was derived from four sources: the Continuing Survey of Food Intakes by Individuals 1994-1996, 
1998 (CSFII $)^{26,27}$, the National Health and Nutrition Examination Survey of 1988-1994 (NHANES) III $^{28}$, the National School Lunch Program (NSLP) ${ }^{29}$ standard serving sizes and from direct observation of children eating snacks in after-school settings. First we identified common sources of calcium in children's diets using national survey data ${ }^{26,28}$ to capture the foods that contribute a majority of calcium in children's diets. In addition, we surveyed new calcium-rich foods or calcium-fortified foods and beverages that were on the market. This yielded an extensive list of foods, and was used to further identify calcium-rich foods consumed by children who were observed in three BONES pilot programmes. Finally we interviewed programme leaders and children regarding their snack and meal pattern to make sure no other calcium-rich foods were missed.

Consistent with national data, the foods consumed by most children were milk, cereal, pizza, and macaroni and cheese. Our observations and review of school meal and snack menus revealed that several foods, such as yoghurt and calcium-fortified foods such as juice, cereal bars, graham crackers and frozen waffles, had become popular since NHANES III, and these foods were also included in the list. To reflect ethnic dietary patterns, specific foods that contribute calcium in some cuisines such as tofu, red beans and rice, bok choy and kale were also added. A juice category included fruit juice, fruit drinks and ades. Soft drinks were included as a dummy category because they often replace calcium-rich beverages such as milk in a child's diet ${ }^{30-32}$ and because the larger BONES study tracked this information. 'Child-friendly' foods such as a hot dog, a hamburger, and a peanut butter and jelly sandwich were also added as 'dummy' foods to mask the purpose of the checklist.

Next, the calcium content of various foods was calculated using standard United States Department of Agriculture (USDA) serving sizes based on NSLP standards for children ${ }^{29}$. We also calculated the calcium content of these same foods using NHANES III $^{28}$ data for 6-11-year-old children. However, there were a limited number of children in this age range consuming these calcium-rich foods (e.g. pudding, fortified juice). In addition, the calcium content per gram of several food items (e.g. milk, broccoli) was similar between NHANES III and NSLP. Therefore, we used the NSLP standard in lieu of data from NHANES III.

Finally, to further refine the checklist, we developed a scrapbook with pictures of common containers and servings of foods to help with recall of foods where serving sizes were observed to be highly variable. These included yoghurt (children selected the container size consumed from a range of widely available single-serving yoghurts) and ice cream (children indicated number of scoops or type of specialty bar). Soft drinks are not part of the NSLP and hence a 6-Oz serving was assigned based on intakes reported by young children in national surveys ${ }^{26,30,33}$.
Table 1 shows the foods in the final calcium checklist; it includes 19 commonly consumed foods and beverages, of which 10 are naturally calcium-rich, five are frequently fortified and four are 'dummy' foods. It was designed to be interviewer administered since parents were not available to assist with dietary reporting.

\section{Subjects and procedures}

The validation study tested the extent to which a child would recall the same foods using two different methods: a parent-assisted 24-h dietary recall and the calcium checklist. All children whose parents had consented to participate in the main BONES study were sent invitations to participate in the validation study by mail. Information describing the dietary recall procedure was sent ahead of time to parents asking them to note and record the general types of foods their children ate. The 44 children who volunteered from 29 BONES after-school programmes in 16 communities came to the USDA Human Nutrition Research Center at Tufts University in Boston, MA, during weekend or school vacation days to participate in the study. The 24-h recall and the calcium checklist were administered in a randomly determined order approximately $1.5 \mathrm{~h}$ apart. Parents assisted children during the 24-h recall, which was considered the reference standard, but were not present during the calcium checklist interview.

The reliability study determined whether the checklist provided consistent results over time. It was conducted among children at six different after-school programmes in six communities during regular programme hours (approximately 2:30-5:30p.m.). Recruitment flyers were posted at the after-school programme so that any child between the ages of 6-10 years attending the programme could participate in it and 56 children volunteered. The calcium checklist was administered twice to each child by two different trained interviewers at least $1 \mathrm{~h}$ apart, and coded as time 1 (T1) and time 2 (T2).

No child who was part of the validation study was part of the reliability study. All procedures were approved by the Tufts University Institutional Review Board and met standard ethical procedures regarding use of children in research. Parents gave their signed, informed consent and children over the age of 7 years gave their written assent.

\section{Parent-assisted 24-b dietary recall}

The 24-h dietary recall interview method was adapted from the standard multiple-pass procedures used in the Nutrition Data System for Research (NDS-R) software (Nutrition Coordinating Center, University of Minnesota, Minneapolis, MN).

During the first pass of the interview, the child was asked to recall all foods, meal by meal that had been consumed over the past $24 \mathrm{~h}$ starting with the most recent meal and going back over the remainder of the period. 
Table 1 Foods on the calcium checklist

\begin{tabular}{|c|c|c|c|}
\hline Food & $\begin{array}{l}\text { Details if food } \\
\text { consumed }\end{array}$ & Serving size if consumed & $\begin{array}{c}\text { Calcium }(\mathrm{mg}) \text { per serving } \\
\text { consumed }\end{array}$ \\
\hline Juice & $\begin{array}{l}\text { Brand/fortified? } \\
\text { Multiple servings? }\end{array}$ & $6 \mathrm{oz}$ & $\begin{array}{l}262.5 \text { if fortified, multiplied } \\
\text { by number of servings }\end{array}$ \\
\hline Milk & $\begin{array}{l}\text { Plain, flavoured, soy } \\
\text { or fortified? } \\
\text { Home or School? } \\
\text { Multiple servings? }\end{array}$ & $80 z$ & $\begin{array}{l}300 \text { for plain, flavoured soy } \\
500 \text { for fortified } \\
\text { Multiplied by total number of } \\
\text { servings }\end{array}$ \\
\hline Yoghurt & $2,4,6$ or 8 oz & Child selects size & $\begin{array}{l}75 \text { for } 2 \text { oz, } 150 \text { for } 4 \text { oz, } \\
225 \text { for } 6 \text { oz, } 300 \text { for } 8 \text { oz }\end{array}$ \\
\hline Cheeset & Slice, string, hard, other & $\begin{array}{l}1.5 \mathrm{oz} \text { if }<9 \text { years } \\
2 \mathrm{oz} \text { if } \geq 9 \text { years }\end{array}$ & $\begin{array}{l}300 \text { if }<9 \text { years, } 400 \text { if } \geq 9 \\
\text { years, } 75 \text { if cottage cheese }\end{array}$ \\
\hline Soda & Caffeinated? & $6 \mathrm{oz}$ & $\mathrm{NA}$ \\
\hline Soup & Cream or broth-based? & 1 cup & 170 if cream-based \\
\hline Cereal & Brand/fortified? & 1 oz or $\frac{3}{4}$ cup & $\begin{array}{l}100 \text { or } 1000 \text { depending on } \\
\text { brand if fortified }\end{array}$ \\
\hline Snack bar & Brand/fortified? & 1 bar & 200 if fortified \\
\hline Waffles or pancakes & Frozen or homemade? & $3.1 \mathrm{~g}$ & 80 if fortified or homemade \\
\hline Ice cream or frozen yoghurt & $\begin{array}{l}1 \text { or } 2 \text { scoops? } \\
\text { Specialty bar? }\end{array}$ & Child selects & $\begin{array}{l}100 \text { if one scoop or } \\
\text { specialty bar } \\
200 \text { if two scoops }\end{array}$ \\
\hline Pudding or custard & No additional details & $\frac{1}{2}$ cup & 150 \\
\hline $\begin{array}{l}\text { Tofu } \\
\text { Rice and beanst }\end{array}$ & $\begin{array}{l}\text { No additional details } \\
\text { No additional details }\end{array}$ & $\begin{array}{l}1.5 \mathrm{oz} \\
\frac{3}{8} \text { cup }\end{array}$ & $\begin{array}{l}270 \\
24\end{array}$ \\
\hline $\begin{array}{l}\text { Peanut butter and jelly } \\
\text { Hotdog with roll } \\
\text { Broccoli, kale, bok choy }\end{array}$ & $\begin{array}{l}\text { No additional details } \\
\text { No additional details } \\
\text { No additional details }\end{array}$ & $\begin{array}{l}1 \text { sandwich } \\
1 \text { hotdog } \\
\frac{1}{2} \text { cup }\end{array}$ & $\begin{array}{l}102 \\
65 \\
47.5\end{array}$ \\
\hline $\begin{array}{l}\text { Hamburger on bun } \ddagger \\
\text { Pizzat } \\
\text { Macaroni and cheeset }\end{array}$ & $\begin{array}{l}\text { No additional details } \\
\text { No additional details } \\
\text { No additional details }\end{array}$ & $\begin{array}{l}1 \text { burger } \\
1 \text { slice }(75 \mathrm{~g}) \\
1 \text { cup }\end{array}$ & $\begin{array}{l}65 \\
388 \\
296\end{array}$ \\
\hline
\end{tabular}

* Picture book used to help child identify brand (juice, cereal, snack bars, frozen waffles/pancakes, soda) or type of food (size of yoghurt container, type of cheese or ice cream); with help, children report number of times they consumed juice and milk, and the type of soup consumed. If brand could not be identified, no calcium is assumed for non-dairy products and a minimal value is assigned for dairy products.

+ Calcium and serving size based on National School Lunch Program standard recipes for age.

¥ If cheeseburger, then cheese recorded as 'slice' under cheese item.

This methodology was used to make the recall task more age-appropriate and comprehensible since children have a limited concept of time ${ }^{4,35}$. During the second pass, food models, bowls, plates, measuring cups and rulers were used to assist in the recall of portion sizes. Parents were instructed to assist children if needed, and typically contributed information regarding the hour of the meal, portion size and preparation. All foods and beverages were recorded by hand and entered into NDS-R software.

\section{Calcium checklist administration}

Trained research assistants used the same methodology for the first pass during the 24-h recall as described above to help the child identify items on the checklist that he/she ate during the reference time period, asking for clarifications when necessary, but without probing or suggesting responses. During the second pass, each item was repeated to the child so that he/she could identify any foods that were missed.

The scrapbook with pictures of various products was shown to the children to obtain specific information about items on the checklist that individual children said they ate. For example, a child who consumed milk was asked to recall the number of times that he/she had milk at home and/or at school. Then, with the help of pictures, the child was asked to indicate whether or not it was chocolate, plain, soy or calcium-fortified. Similarly, if there was a calcium-fortified version of the food, such as juice, cereal or snack bars, the child was shown photographs of actual food containers so that he/she could indicate which brand had been consumed. The interviewer recorded the brand code onto the data sheet for later analysis. Since new products appear frequently on the market, children were instructed to tell the interviewer when they could not find the brand they ate and to describe it if possible, but not to guess.

\section{Statistical analyses}

Data were analysed with SPSS (version 12.0, SPSS Inc., 2003). Parent-assisted 24-h dietary recalls were analysed using NDS-R (version 4.02_30) and transferred into SPSS. Nutrients from foods not included in the NDS-R system were entered by hand. Calcium from dietary supplements was not included in the estimate of the total daily calcium intake because very few children used them. Foods and beverages were then coded by category to match those on the checklist (e.g. milk, yoghurt, cereal) so that 
estimates of calcium intake from a particular food could be assessed by the two methods.

To estimate dietary calcium from the checklist, each item consumed was multiplied by the calcium content of a standard serving based on the USDA's NSLP guidelines (7CFR part 210.10) according to age of the child. For yoghurt the child selected the container size; for ice cream the child selected number of scoops or the specialty bar; and $6 \mathrm{oz}$ was used for soft drinks. Serving sizes were assumed to be whole, not partial, and multiple servings of food items were accounted for in the calculations. Calcium from all items consumed was summed to estimate total calcium intake; calcium from dairy items was summed to estimate total calcium intake from dairy. Since both calcium estimates followed a normal distribution, mean intakes are reported.

Paired $t$-tests were used to compare the mean intake of dietary calcium between recall and checklist in the validation analysis, and between $\mathrm{T} 1$ and $\mathrm{T} 2$ in the reliability analysis, by all subjects and by gender. Tests were considered significant at the $P<0.05$ level. Spearman rank order correlations were used to assess the relationships between overall calcium intake and calcium intake from dairy foods as evaluated by the two methods (recall and checklist) and over time (T1 and T2). In addition, Spearman correlations were also used to assess the effect of individual items in the checklist in order to examine their usefulness individually as well as to examine differences in item efficacy by gender. The Bland-Altman method $^{35}$ was used to examine the measurements of calcium intake obtained by the two methods (recall and checklist). The influences of gender, age and test order on the differences between estimates of total calcium intake from the recall minus calcium intake from the checklist were assessed with regression analysis, as were the effects of individual interviewers and interviewer pairs.

The agreement for consumption of each food item was assessed by method and over time using an agreement score, calculated as the percentage of respondents who answered each question in a similar manner on both recall and checklist and each of the two time points (T1 vs. T2). For example, if a child indicated that a food item was or was not consumed either with both instruments or times points (e.g. a 'yes'-'yes' or a 'no'-'no' response), then agreement was $100 \%$. If the child changed his/her response, then agreement was zero for that item. If a child responded the same way for all 19 items, the per cent agreement was $100 \%$.

\section{Results}

\section{Validation}

Of the 44 children, two were excluded from analysis (for incomplete recall or unsolicited parental assistance during checklist administration), leaving 42 (18 M, 24 F) subjects. Ages ranged from 7.1 to 8.9 years (mean age was 8.0 years); 28 were Caucasian, eight were AfricanAmerican, six were of 'other' race/ethnicities (Hispanic, multi-racial and Native American) and one did not disclose ethnicity.

Mean calcium intake was $1053 \mathrm{mg}$ (SD 502) on the parent-assisted 24-h dietary recall and $935 \mathrm{mg}$ (SD 530) on the checklist (Table 2). Neither the differences in calcium intake for the group as a whole or by gender were significant. Calcium intake estimated from checklist was significantly correlated with that estimated from the recall among girls $(r=0.65, P=0.01)$, but not among boys. In regression models, gender, age, testing order and interviewer pair did not affect the differences between methods in mean calcium intake (data not shown). Mean calcium intakes from dairy products were not significantly different by checklist and recall. Intakes of dairy calcium from recall and checklist were correlated for the group as a whole $(r=0.51, P=0.01)$. Correlations were high among girls ( $r=0.75, P=0.01)$, but not for boys.

The major sources of calcium on the 24-h recall were milk (28\% of total), pizza and cheese (both $13 \%$ of total) and juice ( $9 \%$ of total). The per cent agreement between recall and checklist for consumption of these and other dairy foods ranged from $72 \%$ (juice for boys) to $100 \%$ (milk for boys, and juice and macaroni and cheese for girls).

Figure 1 depicts the limits of agreement in Bland-Altman plots between the mean calcium intake from recall and checklist and the difference between calcium intake as assessed by recall and checklist; all points fell within \pm 2 SDs of the mean difference, although variability increased when calcium consumption rose above $1000 \mathrm{mg}$, indicating that differences between the checklist and the recall were larger at higher intake levels.

Table 2 Dietary calcium intake (mean $\mathrm{mg} \pm \mathrm{SD}$ ) from all foods and from dairy foods by method (parent-assisted 24-h recall vs. calcium checklist), by gender and overall for the group, and Spearman rank correlations for total calcium and calcium from dairy foods

\begin{tabular}{lcccccc}
\hline & $\begin{array}{c}\text { Total calcium } \\
\text { from recall }\end{array}$ & $\begin{array}{c}\text { Total calcium } \\
\text { from checklist }\end{array}$ & $\begin{array}{c}\text { Spearman } \rho \\
\text { (total calcium) }\end{array}$ & $\begin{array}{c}\text { Dairy calcium } \\
\text { from recall }\end{array}$ & $\begin{array}{c}\text { Dairy calcium } \\
\text { from checklist }\end{array}$ & $\begin{array}{c}\text { Spearman } \rho \\
\text { (dairy calcium) }\end{array}$ \\
\hline Boys $(n=18)$ & $1217 \pm 471$ & $983 \pm 513$ & -0.33 & $849 \pm 419$ & $821 \pm 433$ & 0.0 \\
Girls $(n=24)$ & $931 \pm 480$ & $898 \pm 550$ & $0.65^{\star}$ & $584 \pm 421$ & $724 \pm 487$ & $0.75^{\star}$ \\
Total $(n=42)$ & $1053 \pm 502$ & $935 \pm 530$ & 0.28 & $698 \pm 435$ & $766 \pm 462$ & $0.51^{*}$ \\
\hline
\end{tabular}

$\mathrm{SD}$ - standard deviation.

* Significant at $P=0.01$. 

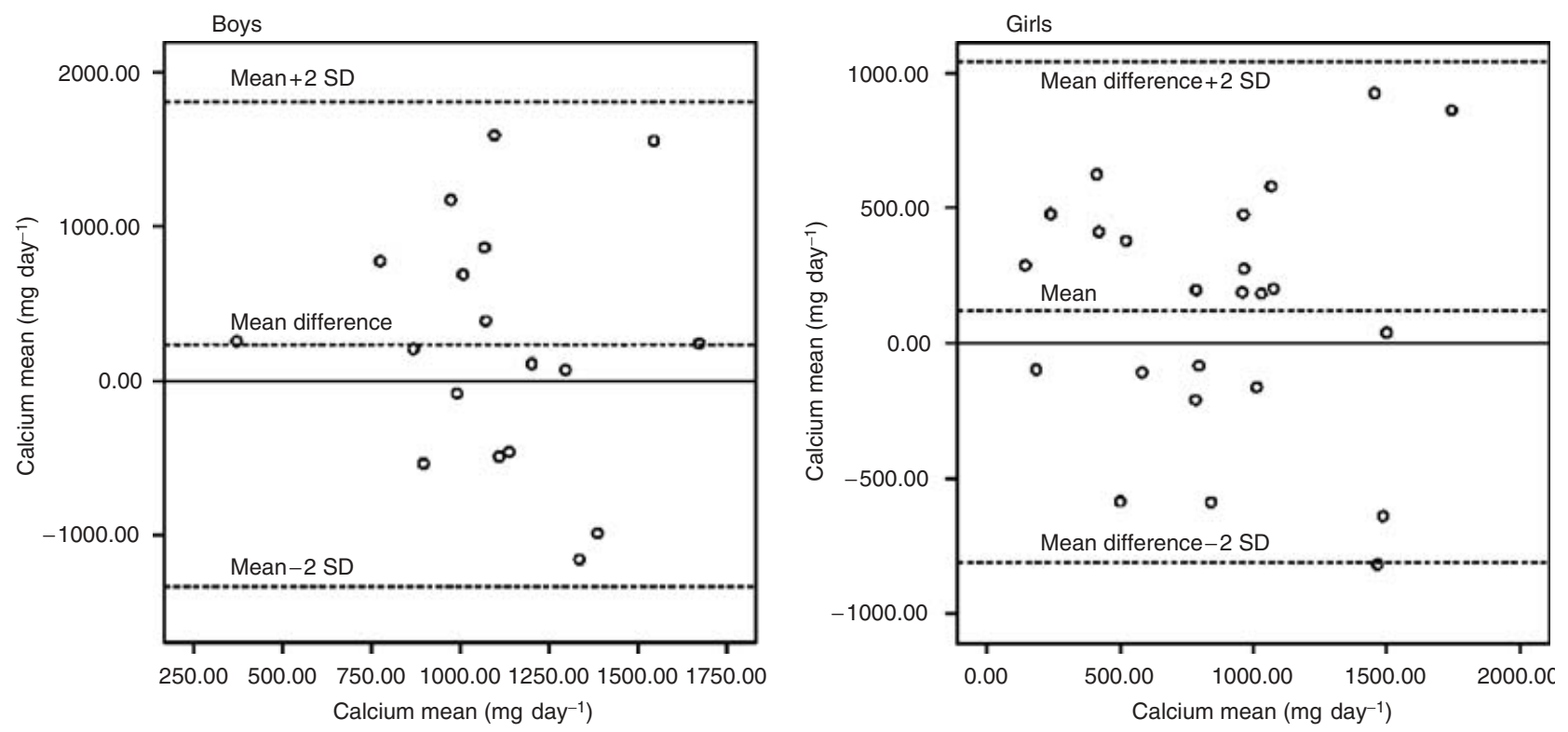

Fig. 1 Limits of agreement of calcium intakes between recall and checklist for boys and girls

Table 3 Total calcium intake (mean $\mathrm{mg} \pm \mathrm{SD}$ ) from all foods on checklist and from dairy at T1 and T2 and Spearman rank correlations

\begin{tabular}{lrrcrrr}
\hline & Calcium T1 & Calcium T2 & $\begin{array}{c}\text { Spearman } \rho \\
\text { (total calcium) }\end{array}$ & Dairy calcium T1 & Dairy calcium T2 & $\begin{array}{c}\text { Spearman } \rho \\
\text { (dairy calcium) }\end{array}$ \\
\hline Boys $(n=28)$ & $978 \pm 573$ & $959 \pm 435$ & $0.49^{\star *}$ & $793 \pm 484$ & $787 \pm 322$ & $0.46^{\star}$ \\
Girls $(n=21)$ & $1256 \pm 578$ & $1117 \pm 590$ & $0.67^{\star * *}$ & $1045 \pm 516$ & $976 \pm 570$ & $0.67^{\star \star *}$ \\
Total $(n=49)$ & $1095 \pm 586$ & $1027 \pm 507$ & $0.58^{\star *}$ & $901 \pm 507$ & $868 \pm 450$ & $0.57^{\star \star *}$ \\
\hline
\end{tabular}

SD - standard deviation; T1 - Time 1; T2 - Time 2.

Significant at ${ }^{*} P<0.05 ;{ }^{* *} P<0.01 ;{ }^{* \star *} P=0.001$.

\section{Reliability}

Of the 55 subjects, seven subjects were excluded (due to absenteeism and/or departure from the after-school programme before completion of both surveys), leaving 49 subjects ( $28 \mathrm{M}, 21 \mathrm{~F}$ ) with complete data for analysis. Ages ranged from 6.6 to 8.4 years (mean age was 7.5 years). Twenty-seven were Caucasian, six African-American, 11 reported other ethnicities and five did not disclose ethnicity.

There were no differences in total calcium intake or calcium from dairy foods reported between T1 and T2 for either girls or boys (Table 3). All correlations were significant at the $P<0.05$ level and ranged from 0.46 (calcium from dairy among boys) to 0.67 (calcium from dairy among girls). Regression analysis showed that age, gender and interviewer pairs did not influence estimates of differences in calcium intakes between $\mathrm{T} 1$ and $\mathrm{T} 2$. The major sources of calcium at T1 were milk $(51 \%$ of total calcium), cheese ( $10 \%$ of total calcium), ice cream ( $8 \%$ of total calcium) and pizza ( $4 \%$ of total calcium).

The per cent agreement for individual food consumption between T1 and T2 was above $80 \%$ for most foods except snack bars (75\%) and cheese (79\%) for boys, and cereal $(71 \%)$ for girls. Correlations between intakes of calcium from specific food items at $\mathrm{T} 1$ and $\mathrm{T} 2$ are shown in Table 4. Correlations for calcium from dairy foods ranged from 0.48 (milk for boys) to 0.93 (ice cream in girls).

Table 4 Spearman correlations for reported calcium intake from checklist foodst for boys and girls from T1 and T2

\begin{tabular}{|c|c|c|}
\hline Food & $\begin{array}{l}\text { Boys }(n=28) \text { : } \\
\text { Spearman } \rho\end{array}$ & $\begin{array}{c}\text { Girls }(n=21) \\
\text { Spearman } \rho\end{array}$ \\
\hline Milk & $0.48^{\star \star}$ & $0.70^{\star \star}$ \\
\hline Yoghurt & $0.71^{\star \star}$ & $0.84^{\star \star}$ \\
\hline Cheese & $0.61^{\star *}$ & $0.61^{\star *}$ \\
\hline Ice cream & $0.67^{\star \star}$ & $0.93^{\star \star}$ \\
\hline Pizza & $0.44^{*}$ & $0.58^{\star \star}$ \\
\hline Macaroni and cheese & $0.68^{\star \star}$ & $0.58^{\star \star}$ \\
\hline Juice & 0.178 & 0.432 \\
\hline Cereal & $0.704^{\star \star}$ & $0.618^{* *}$ \\
\hline Granola bars & -0.090 & $0.580^{\star *}$ \\
\hline Waffles & $0.706^{\star \star}$ & 0.228 \\
\hline Rice and beans & $0.609^{\star \star}$ & $0.676^{\star \star}$ \\
\hline Peanut butter and jelly & $0.650^{\star \star}$ & $1.0^{* *}$ \\
\hline Hamburger & $0.513^{\star \star}$ & $0.583^{* *}$ \\
\hline Hot dog & $0.609^{* *}$ & $0.791^{* *}$ \\
\hline
\end{tabular}

Significant at ${ }^{*} P=0.05 ;{ }^{*} P<0.01$

tThe following items are not reported included in the analysis due to small numbers of children consuming these items: pudding, tofu, broccoli, soup and almonds. 


\section{Discussion}

The checklist we developed to assess calcium intake in early elementary school-aged children without parental assistance provides an alternative to existing methods that require parental input ${ }^{11,17}$, and to FFQs, which are not available for children in this age group ${ }^{3,19,20,36}$. In studies with older children, correlations between information obtained from FFQs and records for calcium intake increase in a linear fashion with age, ranging from 0.35 among 9-11-year olds to 0.59 for 14-18-year-olds $3,19,36$. Our study involved a younger sample of children and, as might be expected, the correlations between calcium intake on dietary recall vs. checklist were modest and somewhat lower for the group as a whole $(r=0.28)$, but higher for girls $(r=0.65)$. Discrepancies between girls and boys may be due to developmental differences. Little information is presently available on such differences in dietary recall ability in early elementary-school children, but other recall studies suggest that gender differences may exist. Among 3-5-year-olds, boys scored higher than girls on a visual-spatial working memory task ${ }^{37}$, while a study with older children and adolescents 9-21-years-old found that girls outperformed boys on a verbal memory $\operatorname{task}^{38}$, although in another study gender differences in memory test performance were not apparent ${ }^{39}$. A fuller understanding of the cognitive processes involved in food recall would be helpful in improving methods for assessing intake in children ${ }^{40}$. Careful training of interviewers and use of standard protocols and assistive materials will maximise the effectiveness and minimise the bias of the checklist.

Study limitations included a small population size, possible recruitment bias into the validation analysis group, the short time interval between administration of the instruments and not accounting for partial servings consumed in the checklist. All interviews were conducted at least $1 \mathrm{~h}$ but no more than $2 \mathrm{~h}$ because of time constraints. Possibly when children were interviewed for a second time they remembered their response from the first rather than recalling this information from memory; however, other studies have also used this same time period in their study designs and have not reported an adverse event ${ }^{41}$. In addition, the reliability study was limited to an assessment of differences in recall of food eaten over one $24-\mathrm{h}$ period. Travel burden on the part of the subjects prevented multiple recall points, so whether the same results would be demonstrated using a second 24-h period remains to be seen.

The use of standard serving sizes for the checklist may lead to under or overreporting of actual calcium intake. For example, the average milk serving size among girls according to the parent-assisted recall was approximately $6 \mathrm{oz}$, while the serving size in the checklist was specified as $8 \mathrm{oz}$, the NSLP standard. Similarly, boys and girls reported drinking approximately $8 \mathrm{oz}$ of juice per serving on the recall, yet the checklist utilised the NSLP standard of a $6 \mathrm{oz}$ serving.

We conclude that this is a reasonably valid, rapid and reliable calcium checklist that can be used to evaluate calcium intake among groups of early elementary schoolaged children in field settings without parental assistance. It performed consistently over time and reliably assessed calcium intakes among the group of girls in comparison to the mean calcium derived from the 24-h recall. However, the accuracy of the checklist needs improvement, especially when it is used among young boys. Further refinement of the checklist may include prompts to improve the accuracy of reported servings of individual food items such as milk or juice, and an option to allow modification of the reference serving sizes of individual foods.

\section{Acknowledgements}

Sources of funding: This research was funded by the National Institutes of Health, 5R01H037752-5 with additional support from the National Dairy Council.

Conflict of interest declaration: C.D.E. serves as a member of the 3-A Day Dairy Advisory Panel.

Authorship responsibilities: L.M., E.H., J.D., J.P.G., E.N.N. and C.D.E. designed the study. L.M., E.H. and C.D.E. were responsible for collection of the data. L.M., E.H., R.R.H., E.N.N. and C.D.E. conducted the analysis. L.M., E.H., J.D., R.R.H., J.P.G., E.N.N. and C.D.E. interpreted the analysis, contributed to writing the manuscript and made substantial conceptual contributions and revisions.

Acknowledgements: We thank Kyla Shea, Eliza Lawson, Andrea Pelletier, Michelle Pacis and Gloria Yu for their assistance with the study.

\section{References}

1 Contento I, Randell J, Basch CE. Review and analysis of evaluation measured used in nutrition education intervention research. Journal of Nutrition Education and Behavior 2002; 34(1): 2-25.

2 McPherson R, Hoelscher D, Alexander M, Scanlon K, Seruda M. Dietary assessment methods among school-aged children: validity and reliability. Preventive Medicine 2000; 31(S): 11-33.

3 Rockett HR, Breitenbach M, Frazier AL, Witschi J, Wolf AM, Field AE, et al. Validation of a youth/adolescent food frequency questionnaire. Preventive Medicine 1997; 26(6): 808-16.

4 Livingstone MB, Robson PJ. Measurement of dietary intake in children. Proceedings of the Nutrition Society 2000; 59(2): 279-93.

5 Treiber FA, Leonard SB, Frank G, Musante L, Davis H, Strong WB, et al. Dietary assessment instruments for preschool children: reliability of parental responses to the 24-hour recall and a food frequency questionnaire. Journal of the American Dietetic Association 1990; 90(6): 814-20. 
6 Stein AD, Shea S, Basch CE, Contento IR, Zybert P. Variability and tracking of nutrient intakes of preschool children based on multiple administrations of the 24-hour dietary recall. American Journal of Epidemiology 1991; 134(12): 1427-37.

7 Sobo EJ, Rock CL, Neuhouser ML, Maciel TL, NeumarkSztainer D. Caretaker-child interaction during children's 24-hour dietary recalls: who contributes what to the recall record? Journal of the American Dietetic Association 2000; 100(4): 428-33.

8 Matheson DM, Hanson KA, McDonald TE, Robinson TN. Validity of children's food portion estimates: a comparison of 2 measurement aids. Archives of Pediatrics and Adolescent Medicine 2002; 156(9): 867-71.

9 Baxter S, Thompson WO, Litaker M, Frye F, Guinn C. Low accuracy and low consistency of fourth-graders' school breakfast and lunch recalls. Journal of the American Dietetic Assocation 2002; 102(3): 386-95.

10 Lytle L, Nichaman M, Obarzanek E, Collaborative Group C. Validation of 24 hour recalls assisted by food records in third grade children. Journal of the American Medical Association 1993; 93: 1431-6.

11 Baranowski T, Islam N, Baranowski J, Cullen KW, Myres D, Marsh T, et al. The food intake recording software system is valid among fourth-grade children. Journal of the American Dietetic Association 2002; 102(3): 380-5.

12 Buzzard IM, Stanton CA, Figueiredo M, Fries EA, Nicholson $\mathrm{R}$, Hogan CJ, et al. Development and reproducibility of a brief food frequency questionnaire for assessing the fat, fiber, and fruit and vegetable intakes of rural adolescents. Journal of the American Dietetic Association 2001; 101(12): 1438-46.

13 Kristal AR, Vizenor NC, Patterson RE, Neuhouser ML, Shattuck AL, McLerran D. Precision and bias of food frequency-based measures of fruit and vegetable intakes. Cancer Epidemiology Biomarkers and Prevention 2000; 9(9): 939-44.

14 Baranowski T, Smith M, Baranowski J, Wang DT, Doyle C, Lin LS, et al. Low validity of a seven-item fruit and vegetable food frequency questionnaire among third-grade students. Journal of the American Dietetic Association 1997; 97(1): 66-8.

15 Edmunds LD, Ziebland S. Development and validation of the Day in the Life Questionnaire (DILQ) as a measure of fruit and vegetable questionnaire for 7-9 year olds. Health Education Research 2002; 17(2): 211-20.

16 Field AE, Colditz GA, Fox MK, Byers T, Serdula M, Bosch RJ, et al. Comparison of 4 questionnaires for assessment of fruit and vegetable intake. American Journal of Public Health 1998; 88(8): 1216-18.

17 Taylor RW, Goulding A. Validation of a short food frequency questionnaire to assess calcium intake in children aged 3 to 6 years. European Journal of Clinical Nutrition 1998; 52(6): 464-5.

18 Brown JL, Griebler R. Reliability of a short and long version of the Block food frequency form for assessing changes in calcium intake. Journal of the American Dietetic Association 1993; 93(7): 784-9.

19 Jensen JK, Gustafson D, Boushey CJ, Auld G, Bock MA, Bruhn CM, et al. Development of a food frequency questionnaire to estimate calcium intake of Asian, Hispanic, and white youth. Journal of the American Dietetic Association 2004; 104(5): 762-9.

20 Magkos F, Manios Y, Babaroutsi E, Sidossis LS. Development and validation of a food frequency questionnaire for assessing dietary calcium intake in the general population. Osteoporosis International 2006; 17(2): 304-12.

21 Crawford PB, Obarzanek E, Morrison J, Sabry ZI. Comparative advantage of 3-day food records over 24-hour recall and 5-day food frequency validated by observation of
9- and 10-year-old girls. Journal of the American Dietetic Association 1994; 94(6): 626-30.

22 Smith KW, Hoelscher DM, Lytle LA, Dwyer JT, Nicklas TA, Zive MM, et al. Reliability and validity of the Child and Adolescent Trial for Cardiovascular Health (CATCH) food checklist: a self-report instrument to measure fat and sodium intake by middle school students. Journal of the American Dietetic Association 2001; 101(6): 635-47.

23 Yaroch AL, Resnicow K, Petty AD, Khan LK. Validity and reliability of a modified qualitative dietary fat index in lowincome, overweight, African American adolescent girls. Journal of the American Dietetic Association 2000; 100(12): 1525-9.

24 Johnson B, Hackett A, Roundfield M, Coufopoulos A. An investigation of the validity and reliability of a food intake questionnaire. Journal of theHuman Nutrition and Dietetics 2001; 14(6): 457-65.

25 Arnold JE, Rohan T, Howe G, Leblanc M. Reproducibility and validity of a food-frequency questionnaire designed for use in girls age 7 to 12 years. Annals of Epidemiology 1995; 5(5): 369-77.

26 United States Department of Agriculture. ARS. Continuing Survey of Food Intakes by Individuals 1994-1996, 1998. Data tables. 1999. Available at http://www.barc.usda.gov/ bhnrc/foodsurvey/home.htm. Accessed 5 March 2003.

27 Subar AF, Krebs-Smith SM, Cook A, Kahle LL. Dietary sources of nutrients among US children, 1989-1991. Pediatrics 1998; 102(4 Pt 1): 913-23.

28 US Department of Health and Human Services (DHHS). National Center for Health Statistics. Third National Health and Nutrition Examination Survey (NHANES), 1988-1994, NHANES III Second Laboratory Data File (CD-ROM, Series 11, No. 2A). Hyattsville, MD: Centers for Disease Control and Prevention, 1998.

29 Federal Register 18147. Subchapter A - Child Nutrition Programs, Part 210 - National School Lunch Program. p. $7-35$.

30 Rampersaud GC, Bailey LB, Kauwell GP. National survey beverage consumption data for children and adolescents indicate the need to encourage a shift toward more nutritive beverages. Journal of the American Dietetic Association 2003; 103(1): 97-100.

31 Nielsen SJ, Popkin BM. Changes in beverage intake between 1977 and 2001. American Journal of Preventive Medicine 2004; 27(3): 205-10.

32 Bowman SA. Beverage choices of young females: changes and impact on nutrient intakes. Journal of the American Dietetic Association 2002; 102(9): 1234-9.

33 US Department of Agriculture and Agricultural Research Service. Data Tables: Results from USDA's 1994-1996 Continuing Survey of Food Intakes by Individuals, 1997. Accessed 7 July 2000.

34 Biro G, Hulshof KF, Ovesen L, Amorim Cruz JA. Selection of methodology to assess food intake. European Journal of Clinical Nutrition 2002; 56(Suppl. 2): S25-32.

35 Chan YH. Biostatistics 302. Principal component and factor analysis. Singapore Medical Journal 2004; 45(12): 558-65, Quiz 66.

36 Field AE, Peterson KE, Gortmaker SL, Cheung L, Rockett H, Fox MK, et al. Reproducibility and validity of a food frequency questionnaire among fourth to seventh grade inner-city school children: implications of age and day-today variation in dietary intake. Public Health Nutrition 1999; 2(3): 293-300.

37 Robinson N, Abbott R, Berninger V, Busse J. The structure of abilities in math-precocious young children: gender similarities and differences. Journal of theEducational Psychology 1996; 88(2): 341-52.

38 Temple C, Cornish K. Recognition memory for words and faces in schoolchildren: a female advantage for 
words. British Journal of Developmental Psychology 1993; 11(4): 421-6.

39 Lowe J, Balanda K, Stanton W, Gillespie A. Evaluation of a three-year school-based intervention to increase adolescent sun protection. Health Education and Behavior 1999; 26(3): 396-408.
40 Baranowski T, Domel SB. A cognitive model of children's reporting of food intake. American Journal of Clinical Nutrition 1994; 59(1 Suppl.): 212S-7S.

41 Weston A, Petosa R, Pate R. Validation of an instrument for measurement of physical activity in youth. Medicine and Science in Sports and Exercise 1997; 29(1): 138-43. 